\title{
Metal Complexes and Free Radical Toxins Produced by Pfiesteria piscicida
}

\author{
Peter D. R. Moeller*, Kevin R. Beauchesne*, Kevin M. Huncik*, W. Clay Davis ${ }^{\dagger}$, Steven \\ J. Christopher ${ }^{\dagger}$, Pamela Riggs-Gelasco ${ }^{\ddagger}$ and Andrew K. Gelasco ${ }^{\S}$ \\ *Toxin/Natural Products Chemistry Program, Center for Coastal Environmental Health \\ and Biomolecular Research, National Oceanic and Atmospheric Administration \\ National Ocean Service, Hollings Marine Laboratory, Charleston, SC 29412; ${ }^{\dagger}$ National \\ Institute of Standards and Technology, Hollings Marine Laboratory, Charleston, SC \\ 29412; 'Department of Chemistry, College of Charleston, Charleston, SC 29424; \\ ${ }^{\S}$ Department of Medicine, Nephrology Division, Medical University of South Carolina, \\ and Research Service, Ralph H. Johnson VA Medical Center, Charleston, SC 29425.
}

Contact Information: peter.moeller@noaa.gov

Phone: (843) 762-8867

Fax: (843) 762-8737

Supplementary Information 